\title{
'The next generation of innovation policy: Directionality and the role of demand-oriented instruments'-Introduction to the special section
}

\author{
Jakob Edler ${ }^{1, *}$ and Wouter P. Boon ${ }^{2}$ \\ ${ }^{1}$ Manchester Institute of Innovation Research, Alliance Manchester Business School, University of Manchester, \\ Manchester, M13 9PL, UK and ${ }^{2}$ Innovation Studies Group, Copernicus Institute Sustainable Development, Utrecht \\ University, Heidelberglaan 2, 3584 CS Utrecht, The Netherlands
}

${ }^{*}$ Corresponding author. jakob.edler@manchester.ac.uk

\begin{abstract}
This editorial introduces the basic idea and content of the special section "the next generation of innovation policy: Directionality and the role of demand side instruments". It highlights the purpose of the special section, i.e. to spark a new debate about innovation policy against the demands for more directionality of policy intervention and the need for policies to actively contribute to system transitions to confront major societal challenges. It summarises the main contribution of each of the articles in the special section.
\end{abstract}

Key words: innovation policy; directionality; societal challenges; demand

Countries around the globe have increasingly turned their attention to grand societal challenges like climate change and healthy ageing. Accordingly, challenges dictate (parts of) their innovation policies. Scholars have recognised that challenges cross various sectors, engage diverse sets of actors, and address multiple objectives (Foray et al. 2012; Kuhlmann and Rip 2014). Such complexity calls for a systemic approach. In such a systemic context, an important dimension of designing challenge-oriented innovation policies forms the articulation of demands and markets, which dictate for a large part the direction policies will take.

This special section brings together various strands of current policy thinking and practice that share an orientation towards directionality of innovation, embracing the idea that beyond supporting the conditions and practices on the supply side to innovate more and faster, policies to support the generation and diffusion of innovation needs to be oriented towards responding to societal needs and demands. As yet, these demand- and solution-oriented strands of policy thinking and practice have not been interacting sufficiently, both conceptually and in terms of policy practice.

The special section seeks to spark a new debate on the meaning of and conditions for policy to support directionality of innovation. In doing so, the special section focuses on the role of demandoriented measures to support directional innovation policy, be it in generic innovation policy, in sectoral policy or in mission-oriented policy which cuts across policy areas.
The collection of the six papers in this special section offers new ways of conceptualising policies in support of the generation and application of innovation which are of immediate usefulness to solve societal problems. As the focus is on problem-solving and societal benefits of innovation, all papers take societal need and the actual use of innovation as the starting point. The papers in the special section offer a wealth of concrete empirical illustrations across a wide range of societal areas and at different levels of government.

Our own paper in this special section (Boon and Edler, this volume) develops a conceptual framework to make sense of the variety of directionality policies. We first conceptualise demand and need, highlight different forms of demand articulation, and then go on to elaborate on the three ideal-typical policies that relate to demand and directionality: traditional innovation policy, sector-specific policy and challenge-oriented policy. The three ideal types are then discussed focusing on output legitimacy, input legitimacy, and operational requirements. This discussion highlights the specific challenges and opportunities of demand- and directionality-oriented innovation policies and allows to derive a set of recommendations to increase the effectiveness of such policies.

The paper by Stefan Kuhlmann and Arie Rip (this volume) first discusses the characteristics that set grand societal challenges apart from other policy categories, especially emphasising the open-ended nature of challenges and the involvement of a wide array of stakeholders. Dealing with challenges thus requires governments to 
embrace a metagovernance perspective that creates conditions for others to self-organise and experiment around societal problems. This signifies a shift from governmental steering towards 'concertation' which leaves governments responsible for organising platforms for collective action, e.g. in the form of public-private partnerships, creating markets and arranging capability and capacity building. This article contributes to the understanding of the changing role of the state, which in order to support transformation to tackle challenge is actually less interventionist and turns more towards supporting societal self-organising of directionality.

The paper by Haico Te Kulve and colleagues (this volume) investigates the role of regulatory authorities in the process of formulating demands and requirements for novel technologies in the case of emerging sensor technologies. These roles range from being directive and forceful to engaging in co-creation activities. The authors show that even if regulatory authorities are not engaged in demand articulation processes they still can influence these processes, as technology developers and users proactively aim to include perceived future regulatory wishes or do not know what to pursue and turn into passivity. Based on this, they call for a more aware, active, and co-creating role for regulators in the early stages of technology development. This would support demand articulation processes and conditions for user-producer interactions to overcome possible impasses and 'waiting games'.

The paper by Markus Bugge and colleagues (this volume) is a case study of a government-led initiative aimed at a transition from reactive to proactive approaches for healthcare provision. They demonstrate the various attempts by governmental and nongovernmental actors to support the use of novel assisted-living technologies. As the success of the transition depends on the buy-in of a broad range of stakeholder groups, and a readiness to learn and adapt behaviour. Government is only one among many actors, and it plays a variety of roles, employing a specific policy mix with some focus on being the orchestrator of stakeholder debates and of initiatives to support demand articulation and directionality of innovation. The authors convincingly show the need for a 'governance mix' and the importance of understanding the conditions for innovation generation and absorption when it comes to support system transitions. In fact, they show that the dichotomies between innovation policy and health policy, and between a top-down and bottom-up approach do not hold any longer.

The remaining two papers focus on the specific state-led activity of public procurement which is too often misunderstood as a simple panacea to generate innovations that are, by default, societally desirable. First, based on a very comprehensive review of diverse but complementary policy and economic literature, Julien Chicot and Mireille Matt (this volume) develop a finely granulated typology of public procurement initiatives which are linked to characteristics of failures. This highlights the diversity of failures and purposes linked to public procurement of innovation (PPI) initiatives, the variety of design elements and the variety of concrete problem constellations. Their typologies allow an improved understanding of PPI activities and problem situations and can thus also guide policy practitioners to develop PPI approaches tailored to specific contextual situations and purposes. Within the grand theme of this special section, this paper highlights the need for a very differentiated conceptualisation of public procurement and its application to understand demand situations and instrumentation.

The second paper concerned with public procurement of innovation combines system transitions and procurement literature. Joeri Wesseling and Charles Edquist (this volume) study procurement for societal challenges in the case of a radically-new flood barrier technology. They find that public procurement for innovation can support transformative processes through intelligent processes of articulation of societal demands, responsive development and production of new technologies, and careful selection, diffusion, and use of new technologies to meet these societal demands. The paper contributes to our understanding of the diverse role of the state in public procurement processes, whereby the state is not simply a buyer, but an orchestrator of articulation and selection processes.

The interplay of conceptualisation and empirical illustrations in the six papers invites the reader to reflect on new ways of organising challenge-oriented innovation policy. Innovation policy shall no longer be seen merely as one specific and stand-alone activity of governments, organised in a distinct ministry and across different levels of policymaking. Rather, it is more appropriate to regard it as a creative way of supporting the societal process of identification and articulation of needs and their translation into concrete market demands. Challenge-oriented innovation policy thus involves designing policy instruments that take this challenge and need-based demand as starting points to support directionality of innovation generation and system conditions. This approach also needs a more flexible organisation of processes within government, whereby policy is most appropriate when it combines the political responsibility of societal problems and the problem-oriented sociopolitical networks on the one hand much more with the know-how about innovation policy instruments, and whereby traditional innovation policy actors play a role of supporting problem- and challenge-oriented policymaking.

\section{References}

Foray, D., Mowery, D. C., and Nelson, R. R. (2012) 'Public R\&D and Social Challenges: What Lessons from Mission R\&D Programs?', Research Policy, 41/10: 1697-702.

Kuhlmann, S., and Rip A. (2014) The Challenge of Addressing Grand Challenges. EU Commission. 